\title{
Fast prediction for multi-parameters (concentration, temperature and humidity) of indoor environment towards the online control of HVAC system
}

\author{
Hao-Cheng Zhu ${ }^{1,3}$, Chen Ren', Shi-Jie Cao ${ }^{1,2}(\bowtie)$ \\ 1. School of Architecture, Southeast University, 2 Sipailou, Nanjing, 21009, China \\ 2. Global Centre for Clean Air Research (GCARE), Department of Civil and Environmental Engineering, Faculty of Engineering and Physical \\ Sciences, University of Surrey, Guildford, Surrey, UK \\ 3. Academy of Building Energy Efficiency, School of Civil Engineering, Guangzhou University, Guangzhou 510006, China
}

\section{Abstract}

Heating, ventilation and air conditioning (HVAC) systems are the most energy-consuming building implements for the improvement of indoor environmental quality (IEQ). We have developed the optimal control strategies for HVAC system to respectively achieve the optimal selections of ventilation rate and supplied air temperature with consideration of energy conservation, through the fast prediction methods by using low-dimensional linear ventilation model (LLVM) based artificial neural network (ANN) and low-dimensional linear temperature model (LLTM) based contribution ratio of indoor climate $\left(\mathrm{CRI}_{\mathrm{T}}\right)$. To be continued for integrated control of multi-parameters, we further developed the fast prediction model for indoor humidity by using low-dimensional linear humidity model (LLHM) and contribution ratio of indoor humidity $\left(\mathrm{CRI}_{(\mathrm{H})}\right)$, and thermal sensation index (TS) for assessment. CFD was used to construct the prediction database for $\mathrm{CO}_{2}$, temperature and humidity. Low-dimensional linear models (LLM), including LLVM, LLTM and LLHM, were adopted to expand database for the sake of data storage reduction. Then, coupling with $A N N, C R I_{(\mathrm{T})}$ and $\mathrm{CRI}_{(\mathrm{H}) \text {, }}$ the distributions of indoor $\mathrm{CO}_{2}$ concentration, temperature, and humidity were rapidly predicted on the basis of LLVM-based ANN, LLTM-based CRI $\left.\right|_{(\mathrm{T})}$ and LLHM-based CRI $\mathrm{I}_{(\mathrm{H}) \text {, }}$ respectively. Finally, according to the self-defined indices (i.e., $E_{\mathrm{V}}, E_{\mathrm{T}}, E_{\mathrm{H}}$ ), the optimal balancing between IEQ (indicated by $\mathrm{CO}_{2}$ concentration, $\mathrm{PMV}$ and TS) and energy consumption (indicated by ventilation rate, supplied air temperature and humidity) were synthetically evaluated. The total HVAC energy consumption could be reduced by $35 \%$ on the strength of current control strategies. This work can further contribute to development of the intelligent online control for HVAC systems.
\end{abstract}

\author{
Keywords \\ HVAC system, \\ indoor air pollution, \\ thermal comfort, \\ indoor humidity, \\ control
}

\author{
Article History \\ Received: 08 May 2020 \\ Revised: 06 August 2020 \\ Accepted: 07 August 2020 \\ (c) The Author(s) 2020
}

\section{Introduction}

HVAC (Heating, ventilation and air conditioning) systems play an important role in improving air quality (Chen et al. 2018) and thermal comfort (Bluyssen et al. 2011; Lai et al. 2020) of building environment. In the region with hot summer and cold winter, HVAC systems are always designed with larger loads to ensure the comfort of occupants and indoor air quality, while it can also cause significant energy consumption, especially in summer (Pérez-Lombard et al.
2008; Kim and Yu 2018). A recent study shows that building energy consumption accounts for $40 \%$ of global final energy use (Yuan et al. 2020). Among the large building energy consumption, HVAC systems account for more than $50 \%$ of the total building energy consumption (Zhuang and Wang 2020; Tian et al. 2020), especially in non-residential buildings (e.g., commercial and office buildings), where the share of energy consumption is as high as $60 \%$ (Grosskopf et al. 2008). However, the traditional operation of HVAC systems cannot be self-adjusted according to the real time

E-mail: shijie_cao@seu.edu.cn 
characteristics of dynamic changes and non-uniform distribution of indoor environment, which can easily cause the comfort instability and energy waste (Ren and Cao 2019a). From the perspectives of the dynamic demands of the indoor environment and the energy efficiency, it seems that the traditional HVAC control methods are no longer stable and reliable (Wang et al. 2020). Therefore, it is of great significance to propose and develop new HVAC control methods following real-time demand with the consideration of dynamic changes and non-uniform distributions of indoor environment.

The HVAC systems are used to regulate indoor ventilation rate (to mitigate pollutant concentration), temperature and humidity to meet the requirements of indoor air quality and thermal comfort (Anand et al. 2020). Different control strategies for HVAC systems in actual operation can result in different parameters of air supply into the room (ASHRAE 2009), which can affect the energy consumption of the HVAC system and the health of indoor personnel. Therefore, researchers have carried out a large number of studies on control methods from multiple aspects, such as HVAC equipment control, online monitoring control, model predictive control (MPC) and building energy management system control (MBC), etc. Ganchev et al. (2019) saved energy consumption of HVAC systems by improving the efficiency of the cooling equipment and optimizing the operating rate of the equipment. Monitoring of indoor ventilation parameters $\left(\mathrm{CO}_{2}\right)$ can be conducted in buildings for the diagnostic control of HVAC systems to save energy (Li et al. 2018). Moroşan et al. (2010) improved regional comfort and energy savings by using decentralized, centralized, and distributed MPCs for simulation of regional temperature regulation. Gul and Patidar (2015) proposed an integrated building energy management system (BMS) to manage and control the HVAC system to save building energy consumption through research and learning on building energy consumption habits. However, these control methods didn't consider the non-uniform distribution of indoor environment parameters along with dynamic changes, and they are not able to quickly respond to instant variation of the indoor environment through the fast prediction of the nonuniform distribution of the indoor environment, thus failing to ensure the actual demand of the indoor air quality and thermal comfort.

For this, a fast-predictive intelligent control for HVAC system based on real-time environmental response (e.g., dynamic sources of pollutants, heat) was proposed to achieve a balanced and coordinated indoor environmental distribution and energy consumption, which is consisted of three key steps: monitoring, prediction and control (Ren and Cao 2020). Monitoring is the use of limited sensors to monitor changes in regulated environmental parameters (e.g., pollutant concentration, temperature), automatically recording monitoring data as input. Based on monitoring data of targeted environment parameters, it is able to make rapid predictions for the non-uniform distributions of indoor environment parameters by using faster-than-real-time prediction models, whose prediction time is much less than the actual diffusion time of indoor environmental parameters, thus making indoor environmental conditioning more safer and reliable (Cao and Ren 2018; Cao 2019). Finally, the predicted indoor environments will be assessed by environmental evaluation indicators, to minimize the energy consumption within acceptable environmental requirements to realize the dynamic control of intelligent HVAC systems. This is also named as intelligent ventilation online control strategy (to largely mitigate indoor air pollution with the maximize ventilation efficiency) (Cao and Ren 2018), where the fast prediction was realized by a combination of lowdimensional linear ventilation model and artificial neural network (i.e., LLVM-based ANN). On the basis of Cao and Ren (2018), Ren and Cao (2019a) further proposed a lowdimensional linear temperature model for the fast prediction of indoor temperature based on $\mathrm{CRI}_{(\mathrm{T})}$ (Zhang et al. 2013) (i.e., LLTM-based $\mathrm{CRI}_{(\mathrm{T})}$ ). Custom evaluation indices for ventilation and temperature were respectively defined, i.e., $E_{\mathrm{V}}$ and $E_{\mathrm{T}}$, further to well regulate the HVAC system (Ren and Cao 2019a).

However, previous studies integrated online control of contaminant concentrations and temperature but without considering the indoor humidity factors on indoor thermal comfort and HVAC energy consumption. Unlike the effect of ventilation rate and temperature, humidity not only affects a person's heat sensation, but also has more of an effect on a person's physical health. For example, low humidity can lead to the symptoms of dry skin, mouth and throat (Hashiguchi et al. 2005), and also induce mucous membrane, eye sensation, bronchitis, asthma, influenza (Sato et al. 2003; Jaakkola et al. 2014), and static electricity (Paasi et al. 2001; Egawa et al. 2002). The high humidity environment can cause dust mites and moulds on building walls, which in turn can lead to poorer indoor conditions, respiratory discomfort and allergic reactions among indoor workers (Fisk et al. 2007). Humidity also has a significant impact on the energy consumption of the HVAC system. It has been shown that in an effective ventilation system, reducing the indoor relative humidity $(\mathrm{RH})$ setting from $60 \%$ to $50 \%$ increases total energy consumption by a maximum of 22.4\% (Fang et al. 2011; Shehadi 2018). Considering that humidity is important for both indoor environment and energy conservation, in this study we aim to incorporate humidity into fast prediction and online control of environmental parameters along with temperature and pollutant concentration. 
In previous work, we have achieved rapid prediction of indoor pollutant concentration and temperature, similarly, for rapid prediction and control of indoor humidity, the establishment of a rapid prediction model is a main focus of achieving online control of indoor humidity. CFD simulation can be effective for indoor humidity, but it will consume a lot of time (Huang et al. 2011). Based on the uniformity of indoor humidity distribution, a low-dimensional humidity model (LLHM) combined with a $\mathrm{CRI}_{(\mathrm{H})}$ prediction (Huang et al. 2011) method (i.e., LLHM-based $\mathrm{CRI}_{(\mathrm{H})}$ ) is proposed to realize rapid prediction of indoor humidity distribution while ensuring the prediction accuracy within the acceptable range. Therefore, for the rapid control of humidity, in order to balance the thermal comfort of the indoor body and energy consumption, the indoor humidity evaluation index $\left(E_{\mathrm{H}}\right)$ has been defined, so that the indoor humidity distribution is evaluated for rapid feedback and control. Up to this point, we propose an online control strategy for the integrated regulation of HVAC systems in terms of ventilation rate, temperature and humidity, potentially based on the adjustment of fan voltage or compressor input voltage. In this work, we use independent control of air conditioning system to regulate temperature and humidity, which can better satisfy indoor environment requirements and effectively save energy consumption (Zhang et al. 2014). The non-uniform distribution of the indoor environment was considered to ensure that the HVAC system control is more accurate and feasible for engineering application. The present work can contribute to HVAC online control with a full consideration of multiple environmental parameters (i.e., ventilation, temperature and humidity) from perspectives of indoor health and energy conservation.

\section{Method}

In this work, integrated HVAC control for indoor environmental parameters was mainly achieved through the three regulation steps of air change rate per hour $(\mathrm{ACH})$, supplied air temperature and humidity, in order to rationally evaluate and optimize the balance between air-conditioning energy consumption and indoor environmental quality (IEQ). Firstly, the ACH was mainly controlled. The CFD simulations of indoor pollutant concentrations were performed based on different input variables (e.g., source intensity and air supply parameters) to establish the initial CFD database. The initial CFD database was expanded through low-dimensional linear ventilation model (LLVM) and the dimension of expansion database was decreased (to reduce the size of the data in the database, e.g., a data storage reduction from $200 \mathrm{MB}$ to $20 \mathrm{~KB}$ ). The low-dimensional pollution data were then combined with the self-defined index $E_{\mathrm{V}}$ to evaluate the indoor pollution distribution status and derive the optimal control strategy for ACH. Secondly, based on the optimal $\mathrm{ACH}$, the inlet temperature was controlled. Different cases with different supply air temperatures can be simulated by CFD in order to establish the temperature distribution database, and the contribution ratio of indoor temperature $\left(\mathrm{CRI}_{(\mathrm{T})}\right)$ was derived from the simulation results. Both the low-dimensional linear temperature model (LLTM) and the $\mathrm{CRI}_{(\mathrm{T})}$ model can rapidly predict the data of indoor temperature, and LLTM can also reduce the amount of database. The low-dimensional temperature data were then combined with the self-defined index $E_{\mathrm{T}}$ to evaluate the indoor temperature distribution status and derive the optimal control strategy for air supply temperature. Thirdly, based on the optimal ACH and supply air temperature, the supply air humidity was regulated. CFD simulations were used to establish the database of indoor humidity distributions under different supply air humidity. And the contribution ratio of indoor humidity $\left(\mathrm{CRI}_{(\mathrm{H})}\right)$ was derived from the simulation results. Both the low-dimensional linear humidity model (LLHM) and the $\mathrm{CRI}_{(\mathrm{H})}$ model can rapidly predict the data of indoor humidity, and the LLHM can reduce the amount of database. The low-dimensional humidity data were then combined with self-defined index $E_{\mathrm{H}}$ to evaluate the indoor humidity distribution status and derive the optimal control strategy for air supply humidity. Finally, the online control of integrated HVAC system was achieved through the regulation of above three environmental factors (this paper focuses on the control strategy for central air conditioning systems in non-residential buildings). See Figure 1 (flowchart) for details.

\subsection{Methods used for Step 1}

\subsubsection{LLVM used for superposition of pollutant concentration fields resulting from multiple pollutant sources}

Based on CFD simulation results, linear ventilation model (LVM) was used to predict the distributions of indoor pollutant (e.g., $\mathrm{CO}_{2}$ ) concentration by using the linear superposition method, which has presumed that indoor pollutant had negligible influence on indoor air motion, and the pollutant concentration field was approximated to be linear (Cao and Ren 2018). Specifically, the pollutant concentration fields produced by multiple pollutant sources were equivalent to the superposition of concentration fields produced by each single source. On the basis of LVM model, low-dimensional linear ventilation model (LLVM) was further proposed to largely reduce the data storage about pollutant concentration fields (Cao and Ren 2018). Figure 2 showed the schematic diagram of low-dimensional discretization process. 


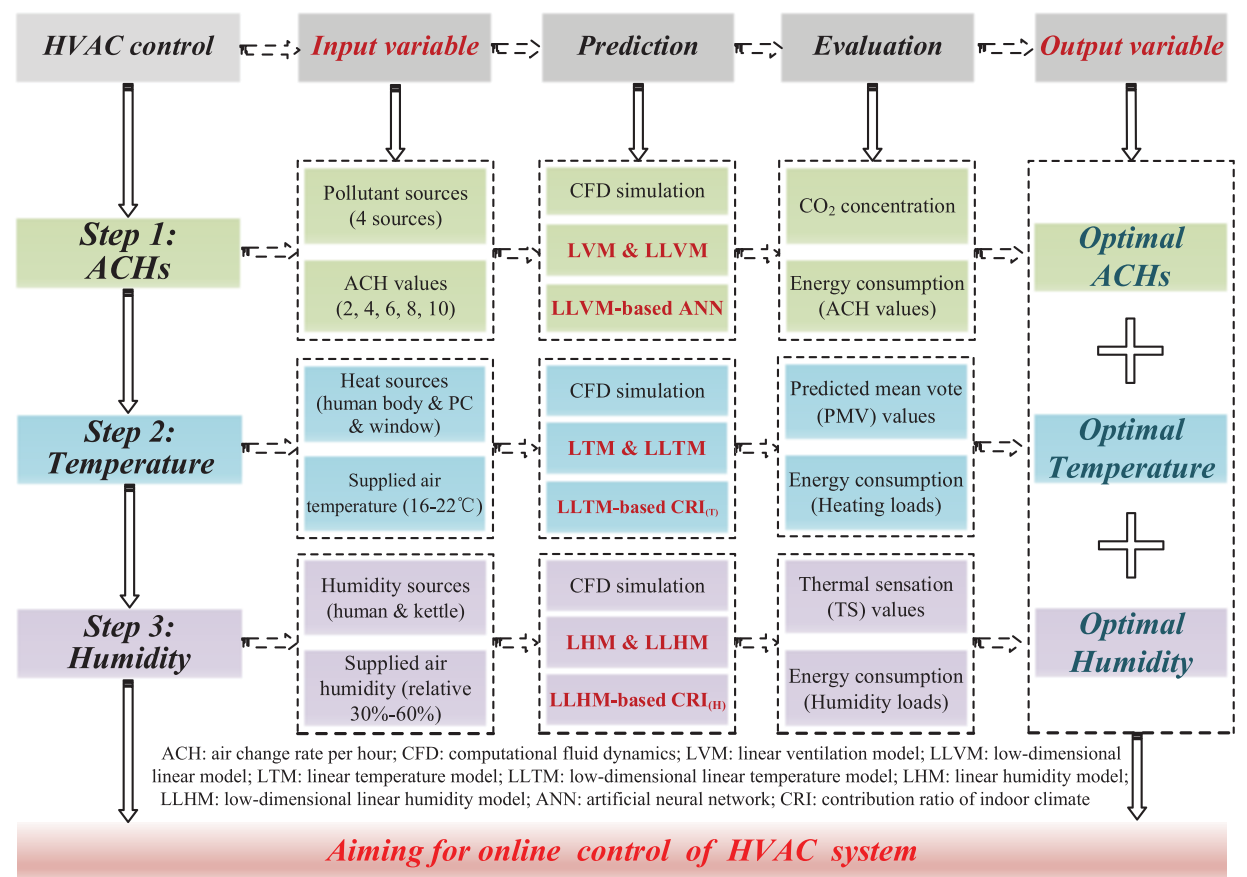

Fig. 1 The flow chart of this work (PMV: predicted mean vote; TS: thermal sensation index)

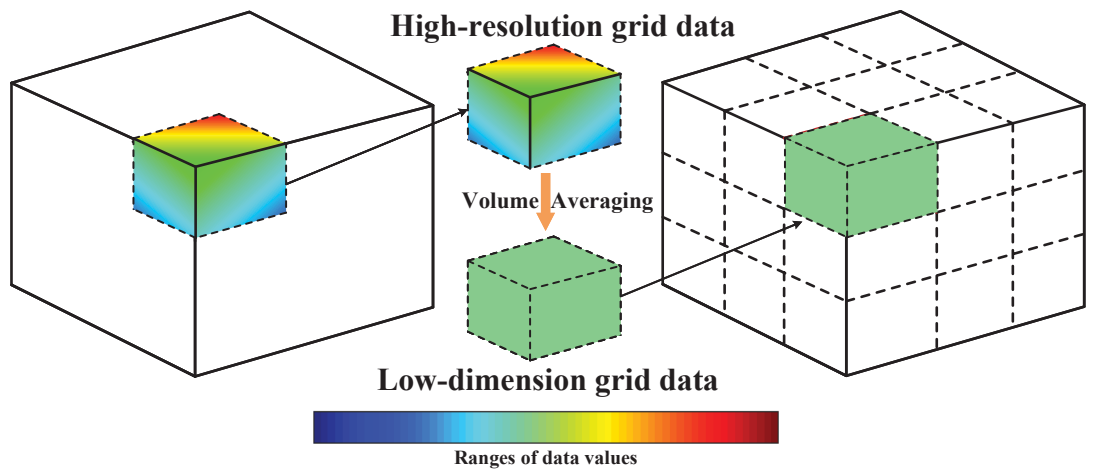

Fig. 2 The schematic diagram of low-dimensional discretization process (Ren and Cao 2019a; reprinted with permission @2019 Elsevier)

\subsubsection{LLVM-based ANN used for fast prediction of pollutant concentration}

On the basis of LLVM, we continued to adopt artificial neural network (ANN) for autonomous learning and rapid prediction of indoor pollutant concentration based on low-dimensional database of concentration fields (Cao and Ren 2018). As one part of machine learning method, ANN was able to rapidly map the relationships between inputs (e.g., position and strength of pollutant source) and outputs (e.g., pollutant concentration). From the above, the method of LLVM-based ANN could be well developed to greatly save the prediction time with the acceptable accuracy for engineering application.

\subsubsection{Evaluation index of $E_{V}$ for optimal ventilation control}

In our previous work, by using the coefficient of variation
(CV) (definitions are found in the Electronic Supplementary Material (ESM) of the online version of this paper), the weightings of $\mathrm{ACH}$ (i.e., ventilation energy consumption) and indoor $\mathrm{CO}_{2}$ concentration (indicated by the averaging $\mathrm{CO}_{2}$ concentration of the breathing region, $C_{\text {mean }}$ ) were respectively calculated (Cao and Ren 2018). The equation of assessment index $E_{\mathrm{V}}$ was shown as follows:

$E_{\mathrm{v}}=W_{\mathrm{v} 1} \frac{\mathrm{ACH}}{\operatorname{Max}(\mathrm{ACH})}+W_{\mathrm{v} 2} \frac{C_{\text {mean }}}{\operatorname{Max}\left(C_{\text {mean }}\right)}$

where, $W_{\mathrm{V} 1}$ and $W_{\mathrm{V} 2}$ are the weights for $\mathrm{ACH}$ and $C_{\text {mean }}$ respectively. On the basis of index $E_{\mathrm{V}}$, The $\mathrm{ACH}$ in the minimum $E_{\mathrm{V}}$ value corresponds to the optimal $\mathrm{ACH}$. Thus, the optimal selections of $\mathrm{ACH}$ can be determined under different conditions of different $\mathrm{CO}_{2}$ source strength and positions. 


\subsection{Methods used for Step 2}

\subsubsection{LTM and LLTM-based CRI (T) used for fast prediction of temperature fields}

Similar to LVM model, Ren and Cao (2019a) also proposed linear temperature model (LTM). The premise of LTM was that if the buoyancy resulting from indoor temperature variation had negligible effect on the indoor airflow, the temperature field can be approximately considered to be linear (Zhang et al. 2013), i.e., the temperature fields caused by multiple heat sources were equal to the superposition of temperature fields caused by these single sources. On the basis of LTM and low-dimensional discretization process, low-dimensional linear temperature model (LLTM) was also proposed.

Regarding $\mathrm{CRI}_{(\mathrm{T})}$ (contribution ratio of indoor climate) model, the definition was the ratio of indoor temperature increase (or decrease) at any position produced by the heat source to the absolute value of indoor temperature increase (or decrease) produced by the same heat source with the increasing (or decreasing) heat quantity diffused uniformly (Zhang et al. 2013). The specific $\mathrm{CRI}_{(\mathrm{T})}$ of the heat source was defined as shown in the ESM of the online version of this pape (Zhang et al. 2013; Ren and Cao 2019a). According to the well-performed CRI $(\mathrm{T})$ and LLTM, LLTM-based CRI $\mathrm{I}_{(\mathrm{T})}$ model was further proposed for fast and efficient prediction of indoor temperature fields, similar to the idea of LLVMbased ANN model for fast prediction of indoor air pollution (Ren and Cao 2019a).

\subsubsection{Evaluation index of $E_{T}$ for optimal temperature control}

Based on the optimal $\mathrm{ACH}$ selection, the index $E_{\mathrm{T}}$ mainly focused on the balancing of supply air temperature (i.e., cooling loads) and PMV (calculate by average temperature of the room) values. With the corresponding weighting coefficients calculated by $\mathrm{CV}$ method, the equation of $E_{\mathrm{T}}$ was defined as follows (Ren and Cao 2019a).

$E_{\mathrm{T}}=W_{\mathrm{T} 1} \frac{|\mathrm{PMV}|}{\operatorname{Max}(|\mathrm{PMV}|)}+W_{\mathrm{T} 2} \frac{T}{\operatorname{Max}(T)}$

where, $W_{\mathrm{T} 1}$ and $W_{\mathrm{T} 2}$ are the weightings for PMV (absolute value) and supply air temperature, respectively. Besides, PMV is calculated by the average room air velocity $\left(V_{\mathrm{R}}\right)$ and temperature $\left(T_{R}\right)$ (Deng et al. 2018), as shown below:

$\mathrm{PMV}=-\frac{7}{83} T_{\mathrm{R}} V_{\mathrm{R}}+\frac{28}{75} T_{\mathrm{R}}-\frac{689}{74}$

On the basis of index $E_{\mathrm{T}}$, the supply air temperature $(T)$ in the minimum $E_{\mathrm{T}}$ value corresponds to the optimal supply air temperature. Thus, the optimal choice of supply air temperature is obtained for conditions of varying intensity and heat source location.

\subsection{Methods used for Step 3}

\subsubsection{LHM used for superposition of humidity field}

Indoor humidity environments can be resulted from different sources of moisture, e.g., human body, equipment, building envelope, and outdoor air. Ventilation airflow pattern can affect the distribution of indoor humidity. In the current study, we assumed that the inlet ACH was constant (continued with the previous steps), and the airflow field was considered to be fixed. Thus, the influence of indoor airflow on humidity fields was not focused in this work. According to the study of Huang et al. (2011), with the indoor moisture assumed to be passively scalar, if the humidity distributions caused by each moisture source were obtained individually, indoor humidity values would be the linear summation of the rises (or falls) in humidity caused by each moisture source. Therefore, we can firstly calculate the humidity fields caused by each humidity source independently, and then obtain the distributions of indoor humidity fields resulting from multiple humidity sources through linear superposition method as LVM and LTM, namely as linear humidity model (LHM).

\subsubsection{LLHM-based CRI $I_{(H)}$ for fast prediction of humidity field}

The contribution rate of indoor climate for humidity $\mathrm{CRI}_{(\mathrm{H})}$ was utilized to judge the influence of various moisture sources on indoor humidity distribution. According to Huang et al. (2011), $\mathrm{CRI}_{(\mathrm{H})}$ indicated the ratio of the rise (or fall) in humidity at a point from an individual moisture source to the rise (or fall) in humidity with the perfect mixing conditions for the same moisture source. The equation of $\mathrm{CRI}_{(\mathrm{H})}$ can be defined as follows:

$$
\mathrm{CRI}_{(\mathrm{H})}(x, n)=\frac{\delta X(x, n)}{X_{n}}, \quad X_{n}=\frac{q_{n}}{\rho \cdot Q}
$$

where, $\delta X(x, n)$ is the rise (or fall) in humidity value from standard status at a point $x$ due to the $n$th moisture source $\left[\mathrm{kg} / \mathrm{kg}\right.$ ']; $X_{n}$ is the rise (or fall) in humidity value under the perfect mixing conditions due to the $n$th moisture source $\left[\mathrm{kg} / \mathrm{kg}^{\prime}\right] ; q_{n}$ is the moisture flux generated by the $n$th moisture source $[\mathrm{kg} / \mathrm{s}] ; \rho$ is the air density $\left[\mathrm{kg}^{\prime} / \mathrm{m}^{3}\right]$; and $Q$ is the air flow rate $\left[\mathrm{m}^{3} / \mathrm{s}\right]$ (Huang et al. 2011). Similar to LLTM-based $\mathrm{CRI}_{(\mathrm{T})}$, low-dimensional humidity model (LLHM)-based CRI $\mathrm{I}_{(\mathrm{H})}$ was proposed in this paper with the combinations of LHM, low-dimensional discretization process and $\mathrm{CRI}_{(\mathrm{H})}$. 


\subsubsection{Transferring absolute humidity to relative humidity}

Since that the prediction results from LLHM-based CRI $\mathrm{H}_{(\mathrm{H})}$ were absolute humidity which cannot be directly controlled, the transformation from absolute humidity to relative humidity should be carried out, according to the following formulas:

$$
\begin{aligned}
& h_{\mathrm{a}}=1.006 t_{\mathrm{a}}+w\left(2501+1.86 t_{\mathrm{a}}\right) \\
& w=0.622 \frac{\varphi P_{\mathrm{sw}}}{P_{\mathrm{b}}-\varphi P_{\mathrm{sw}}} \\
& \ln P_{\mathrm{sw}}=C_{1} / T_{\mathrm{a}}+C_{2}+C_{3} T_{\mathrm{a}}+C_{4} T_{\mathrm{a}}^{2}+C_{5} T_{\mathrm{a}}^{3}+C_{6} \ln T_{\mathrm{a}}
\end{aligned}
$$

where, $t_{\mathrm{a}}$ is the air dry-bulb temperature $\left({ }^{\circ} \mathrm{C}\right) ; w$ is the moisture content $(\mathrm{kg} / \mathrm{kg}$ for dry air); $\varphi$ is the relative humidity; $P_{\mathrm{sw}}$ is the saturation vapor pressure over liquid water $(\mathrm{Pa}) ; P_{\mathrm{b}}$ is the atmosphere pressure $(\mathrm{Pa}) ; C_{1}$ to $C_{6}$ ware the regression coefficients indicated in Table 1 ; and $T_{\mathrm{a}}$ is the absolute air temperature (K) (ASHRAE 2009; Jia and Lee 2015; Feng et al. 2018).

\subsubsection{Evaluation index of $E_{H}$ for optimal relative humidity control}

On the basis of optimal evaluations of $\mathrm{ACH}$ and supplied air temperature, this work further defined the evaluation index $E_{\mathrm{H}}$ to assess the balancing between indoor personal perception of humidity values and air-conditioning energy consumption (i.e., humidity loads), so as to obtain the optimal supplied air humidity. The supply air relative humidity $(H)$ in the minimum $E_{\mathrm{H}}$ value corresponds to the optimal supply air humidity. Combined with weighting coefficients from $\mathrm{CV}$ method, the equation of $E_{\mathrm{H}}$ was shown as follows (the value of TS was calculated by the average relative humidity of the room):

$E_{\mathrm{H}}=W_{\mathrm{H} 1} \frac{\mathrm{TS}}{\operatorname{Max}(\mathrm{TS})}+W_{\mathrm{H} 2} \frac{H}{\operatorname{Max}(H)}$

where, $W_{\mathrm{H} 1}$ and $W_{\mathrm{H} 2}$ are the weightings for thermal sensation (TS) and supply air relative humidity $(H)$, respectively. The expression of index TS is presented as below (de Paula Xavier and Roberto 2000):

$\mathrm{TS}=0.219 T_{0}+0.012 \mathrm{RH}-0.547 \mathrm{~V}_{\mathrm{a}}-5.83$

where, $T_{0}$ is the temperature $\left({ }^{\circ} \mathrm{C}\right) ; \mathrm{RH}$ is the relative humidity $(\%)$; and $V_{\mathrm{a}}$ is the air velocity $(\mathrm{m} / \mathrm{s})$. The scales of thermal sensation (TS) were indicated in Table 2.

Table 1 The coefficients $C_{1}$ to $C_{6}$ in Eq. (7)

\begin{tabular}{ccccccc}
\hline Coefficient & $C_{1}$ & $C_{2}$ & $C_{3}$ & $C_{4}$ & $C_{5}$ & $C_{6}$ \\
\hline Constant & $-5.8 \mathrm{e}+03$ & 1.391 & $-4.864 \mathrm{e}-02$ & $4.176 \mathrm{e}-05$ & $-1.445 \mathrm{e}-08$ & 6.546 \\
\hline
\end{tabular}

Table 2 Assessment scales of thermal sensation (TS)

\begin{tabular}{ccccccc}
\hline \multicolumn{7}{c}{ TS sensations scale } \\
\hline Cold & Cool & Slightly cool & Neutral & Slight warm & Warm & Hot \\
\hline-3 & -2 & -1 & 0 & 1 & 2 & 3 \\
\hline
\end{tabular}

To sum up, on the strength of the rapid prediction of indoor pollutant concentration, temperature as well as humidity fields respectively from LLVM-based ANN, LLTMbased $\mathrm{CRI}_{(\mathrm{T})}$ and LLHM-based $\mathrm{CRI}_{(\mathrm{H})}$, online control of HVAC system (aiming for the optimal selections of supplied loads) can be well proceeded with the assistance of three evaluation indices $E_{\mathrm{V}}, E_{\mathrm{T}}$ and $E_{\mathrm{H}}$.

\subsection{Descriptions of simulations for three steps}

The full-scale experiment chamber used in this study was descripted in Figure 3(a), which was also used for previous work (Cao and Ren 2018; Ren and Cao 2019a). CFD simulations were corresponding to the chamber set up. The full size of this chamber is $3.5 \mathrm{~m}$ (length) $\times 3.4 \mathrm{~m}$ (width) $\times$ $2.5 \mathrm{~m}$ (height). Multiple diffusers were installed along the wall and ceiling to achieve the adjustment of different ventilation modes. In this study, we only considered the ventilation mode with side supply and side return grilles. Of this mode, inlet- 1 and inlet- 2 were both located on the side wall with the size of $18 \mathrm{~cm}$ (length) $\times 18 \mathrm{~cm}$ (width). The outlet was located on the same side wall with the size of $18 \mathrm{~cm}$ (length) $\times 18 \mathrm{~cm}$ (width). Besides, the mesh grids for CFD simulations were with the grid number of 2123820 . Turbulence models were selected for simulations with re-normalization group (RNG) $k-\varepsilon$ model for pollutant concentration and temperature (Ren and Cao 2019a) and low Reynolds number $k-\varepsilon$ model for humidity simulation (Huang et al. 2011). In previous studies, numerous experiments using this chamber were carried out for the validation of simulation results about pollutant concentration and temperature with the maximum errors below $20 \%$, thus CFD simulations have shown good performance and reliability for this study.

\subsubsection{Settings of input variables in Step 1 for pollutant concentration simulation}

In this work, we set four locations of pollution sources respectively corresponding to $\mathrm{A}(0.875,2.55,1.1) \mathrm{m}, \mathrm{B}(2.625$, $2.55,1.1) \mathrm{m}, \mathrm{C}(0.875,0.85,1.1) \mathrm{m}$ and $\mathrm{D}(2.625,0.85,1.1) \mathrm{m}$, as shown in Figure 3(b). For a single pollutant source, the release rate was set as $5 \times 10^{-6} \mathrm{~kg} / \mathrm{s}$ and the background concentration value (molar fraction) was initialized to $5 \times 10^{-4}$ (500 ppm) (Chow 2002). The ACH values of 2, 4, 6,8 and 10 were considered as the initial conditions for the construction of CFD database. The ACH values were 


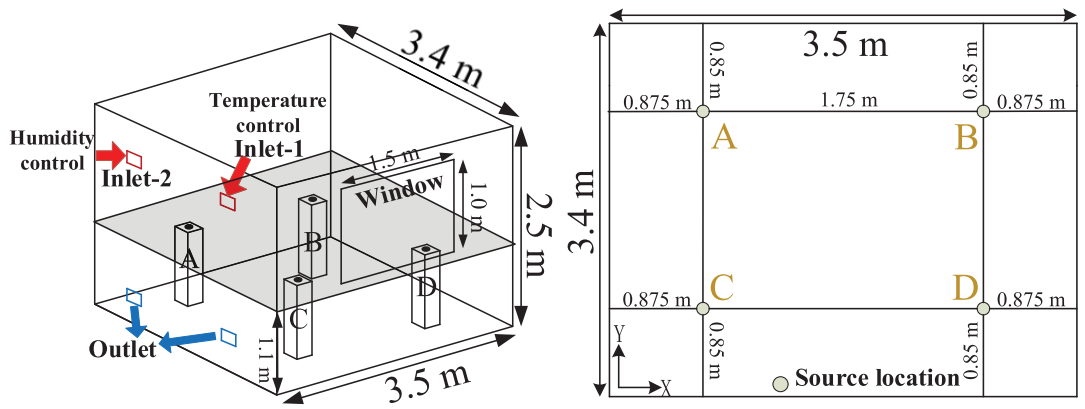

Fig. 3 (a) Ventilation mode and (b) location coordinates of four $\mathrm{CO}_{2}$ sources, i.e., A, B, C and D

calculated by the supply air volume at the ventilation inlets, and the optimal ACH selection was realized based on the above model in Section 2.1.

\subsubsection{Settings of input variables in Step 2 for temperature simulation}

Corresponding to the locations of pollutant sources (ref., Figure 3), four heating sources were set in this work with the same size of $0.2 \mathrm{~m}$ (length) $\times 0.2 \mathrm{~m}$ (width) $\times 1.1 \mathrm{~m}$ (height). One single heating source can stand for the combination of one human body and one personal computer. The intensity settings of heating sources were shown in Table 3 (Zhang et al. 2013; Zhang et al. 2019), and all heat sources were defined by user-defined function (UDF). Besides, another heat source standing for the heat dissipation of window was set on the east wall (with the wall thickness equal to $0.2 \mathrm{~m}$ ) of the chamber, and the size of window was $1.5 \mathrm{~m}$ (length) $\times 1.0 \mathrm{~m}$ (width) $\times 0.01 \mathrm{~m}$ (height) (Ren and Cao 2019a). In this work, the outdoor temperature (i.e., surface temperature of window) was set as $30.7^{\circ} \mathrm{C}(303.7 \mathrm{~K})$. Since that inlet- 1 was responsible for indoor temperature control in this study, the adjustment ranges of supplied air temperature for inlet- 1 were set as $16-22{ }^{\circ} \mathrm{C}(289-295 \mathrm{~K})$. Different from inlet-1, the supplied air temperature of inlet-2 (used for humidity control) was set as $26^{\circ} \mathrm{C}$. Studies have showed that $26^{\circ} \mathrm{C}$ was used as the standard indoor temperature, with a small difference in thermal comfort and perceived air quality under the high and moderate humidity conditions (GB50019-2003 2004; He et al. 2017). It should also be noticed that the above adjustments of supplied air temperature were all based on the optimal $\mathrm{ACH}$ selection results.

Table 3 Thermal parameters of heating sources including human body, personal computer and window

\begin{tabular}{ccccccc}
\hline \multicolumn{9}{c}{ Heat source (human body) } & \multirow{2}{*}{ Personal } \\
& A & B & C & D & Window & computer \\
\hline $\begin{array}{c}\text { Source } \\
\text { intensity }\end{array}$ & $85 \mathrm{~W}$ & $85 \mathrm{~W}$ & $85 \mathrm{~W}$ & $85 \mathrm{~W}$ & $6.17 \mathrm{~W} /\left(\mathrm{m}^{2} \cdot \mathrm{K}\right)$ & $50 \mathrm{~W}$ \\
\hline
\end{tabular}

\subsubsection{Settings of input variables in Step 3 for humidity simulation}

According to ASHRAE Standard, 30\%-60\% of relative humidity $(\mathrm{RH})$ was required in the office buildings for acceptable thermal comfort (ASHRAE 2009). Moreover, a correlational study suggested that $\mathrm{RH}$ values ranging around $45 \%$ may cause neglected influence to people's subjective feeling (Razjouyan et al. 2020). Therefore, in this work, the constant relative humidity value of inlet-1 was set as $45 \%$, and the ranges of supplied air relative humidity for inlet- 2 were set as $30 \%-60 \%$, based on the optimal selections of supplied air temperature. Besides, four humidity sources with the size of $0.45 \mathrm{~m}$ (length) $\times 0.33 \mathrm{~m}$ (width) $\times 0.88 \mathrm{~m}$ (height) (Huang et al. 2011) were designed with the locations respectively corresponding to pollutant sources $A, B, C$ and $\mathrm{D}$ (ref., Figure 3 ). One single humidity source can stand for one human body and one object (e.g., kettle as moisture generator) with the moisture released. Although a certain amount of moisture could transfer through the wall in the actual situation, we mainly focused on the humidity variations of indoor personnel, object and inlet in this work. Thus, the walls with small moisture release were not considered as the separate humidity source.

Regarding the strength of humidity source, the total moisture generation rate (respiration and transpiration) for one occupant was suggested as $60 \mathrm{~g} / \mathrm{h}$, which corresponded to the metabolic rate of an average adult performing typical office work (Popescu-Croitoru 2011). Moreover, the moisture generation rate of kettles around indoor workers is close to $40 \mathrm{~g} / \mathrm{h}$ (Huang et al. 2011). We continued to use UDF method to define the humidity sources for CFD simulation. More details of simulation conditions were shown in Table 4.

\section{Results}

In this section, we mainly adopted fast prediction models to predict indoor environmental fields (i.e., pollutant concentration, temperature and humidity fields). Then, three corresponding self-defined evaluation indices $\left(E_{\mathrm{V}}, E_{\mathrm{T}}, E_{\mathrm{H}}\right)$ 
Table 4 Conditions and settings for humidity simulation.

\begin{tabular}{ll}
\hline \multicolumn{1}{c}{ CFD model } & \multicolumn{1}{c}{ Low Reynolds number $k-\varepsilon$ model } \\
\hline Mesh & 2123820 \\
\hline Differencing scheme & Convection term: Second order upwind \\
\hline \multirow{2}{*}{ Air inlet } & $\begin{array}{l}\text { Velocity: based on the optimal ACH value } \\
\text { Humidity: inlet-1: } 45 \% \text { relative humidity. } \\
\text { Inlet-2: } 30 \%-60 \% \text { relative humidity }\end{array}$ \\
\hline Moisture generation & Moisture(human): 60g/h; Moisture(kettle): $40 \mathrm{~g} / \mathrm{h}$ \\
\hline Wall & Material: no moisture generation, Others: no-slip \\
\hline
\end{tabular}

were applied to obtain the optimal control solutions of HVAC system. The control processes were divided into three parts: (i) In Step 1, the accuracy of LLVM-based ANN model was verified, followed by the comprehensive evaluation of indoor pollutant concentrations and energy consumption based on $E_{\mathrm{V}}$ to determine the optimal ventilation rate $(\mathrm{ACHs})$; (ii) In Step 2, on the basis of optimal ACHs, the accuracy of LLTM-based CRI (T) $_{\text {T }}$ model was verified followed by the evaluation of indoor thermal comfort (expressed as predicted mean vote, $\mathrm{PMV}$ ) and air-conditioning cooling load with $E_{\mathrm{T}}$ to determine the optimal inlet-1's supply air temperature; (iii) In Step 3, on the basis of optimal ACH and supply air temperature, we further verified the accuracy of LLHM-based $\mathrm{CRI}_{(\mathrm{H})}$ model. According to the index $E_{\mathrm{H}}$, the balance between indoor thermal comfort and humidity load was well evaluated, with the optimal inlet-2's relative humidity (RH) obtained. Combined with the above steps, the optimal control of HVAC system was achieved through the comprehensive and sequential regulation of $\mathrm{ACHs}$, temperature and humidity.

3.1 Step 1: selection of the optimal ACH for indoor air pollution $\left(\mathrm{CO}_{2}\right)$ control by using LLVM-based ANN methods

The method of LLVM-based ANN was mainly employed to rapidly predict indoor $\mathrm{CO}_{2}$ concentration fields. According to the method part, we utilized LLVM to rapidly extend the database, and the validation results between LLVM and CFD were shown in Figure 4. The mean deviation error of the $\mathrm{CO}_{2}$ concentrations between LLVM and CFD was less than $13 \%$. With pollutant source locations as inputs, LLVMbased ANN model was able to largely improve the prediction efficiency of $\mathrm{CO}_{2}$ concentrations. As shown in Figure 4, the depiction of $\mathrm{CO}_{2}$ concentration from LLVM-based ANN was in good agreement with CFD simulation along with the mean error less than $15 \%$ (when $\mathrm{ACH}$ is 8 , it is a training set containing more than 2 million grid points of data, and the test set $\mathrm{ACH}$ is 4 , the output is more than 2 million grid points of data, within the acceptable margin of error for engineering application).

High ventilation rates can mitigate the concentration of indoor pollutants (such as $\mathrm{CO}_{2}$ in the current study). However, holding up to the high $\mathrm{ACH}$ value can also result in the large amount of ventilation energy consumption (Cao et al. 2016). Therefore, with the assistance of fast prediction results of indoor $\mathrm{CO}_{2}$ concentration and self-defined evaluation index $E_{\mathrm{V}}$ (shown in Eq. (1)), we comprehensively assessed the balance between indoor $\mathrm{CO}_{2}$ concentration levels and energy consumption (ventilation rate) by calculating the $E_{\mathrm{V}}$ values, as shown in Table 5, The lowest $E_{\mathrm{V}}$ value corresponded to the optimal selection of the targeted $\mathrm{ACH}$ value, i.e., 4 in the current work.

3.2 Step 2: optimization of cooling load for indoor temperature regulation using LLTM-based $\mathrm{CRI}_{(\mathrm{T})}$ method based on optimal ACH

Based on the optimal ACH values, we came to the optimization of cooling load (supply air temperature) of HVAC systems. By comparing the prediction results from LTM (lowdimension temperature model) and CFD, Ren and Cao (2019a) demonstrated that the prediction accuracy of LTM was below $20 \%$ to meet the demands of engineering
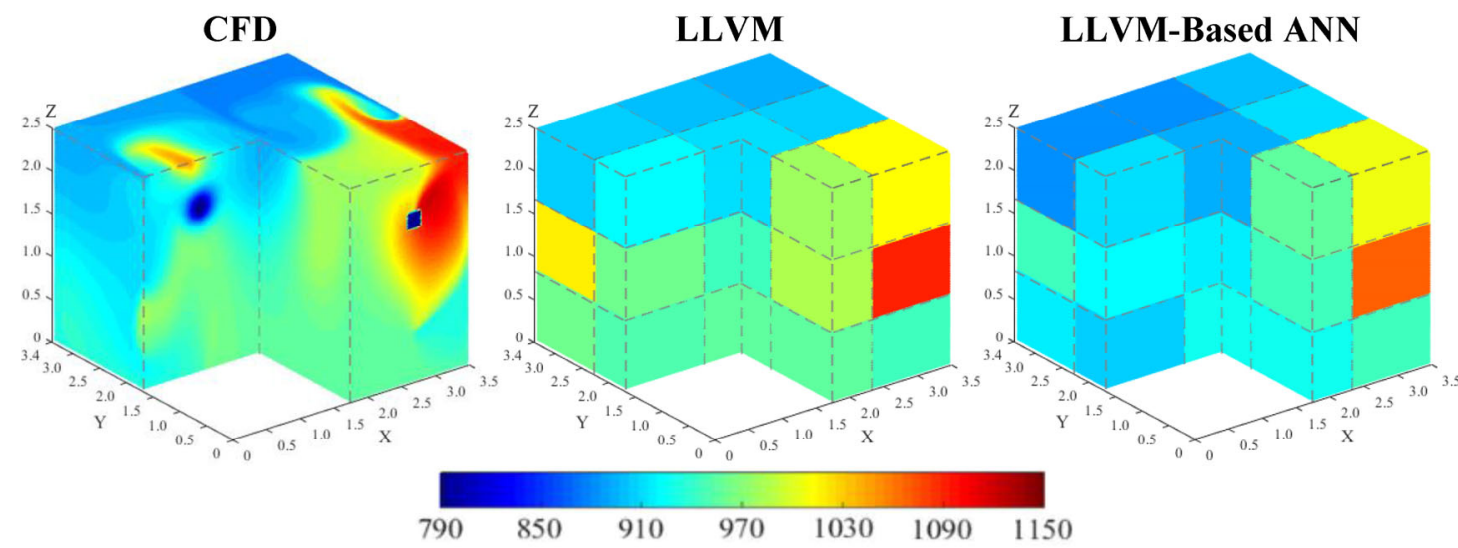

Fig. 4 Comparisons of $\mathrm{CO}_{2}$ concentrations (ppm) between CFD, LLVM and LLVM-based ANN when ACH equal to 4 
Table 5 The calculated results of $E_{\mathrm{V}}$ index for different inlet ACHs

\begin{tabular}{cccccc}
\hline $\mathrm{ACH}$ & 2 & 4 & 6 & 8 & 10 \\
\hline$E_{\mathrm{V}}$ & 0.54 & 0.51 & 0.62 & 0.74 & 0.80 \\
\hline
\end{tabular}

application. Then, we further employed the CFD simulation to verify LLTM (low-dimensional linear temperature) model. As shown in Figure 5, the LLTM method was adopted to obtain low-dimensional discrete data of indoor temperature fields with the inlet-1's supply air temperature equal to $17{ }^{\circ} \mathrm{C}$ and $20^{\circ} \mathrm{C}$, respectively. The maximal temperature deviation between CFD and low-dimensional data from LLTM was less than $2 \mathrm{~K}$. Thus, well-behaved LLTM method can be further employed for the rapid prediction of indoor temperature fields by combing $\mathrm{CRI}_{(\mathrm{T})}$ model.

According to $\mathrm{CRI}_{(\mathrm{T})}$ equation in Eq. (S1), the distributions of $\mathrm{CRI}_{(\mathrm{T})}$ were calculated with the inlet-1's temperature equal to $16^{\circ} \mathrm{C}$ (as shown in the ESM of the online version of this paper). With the combination of LLTM and CRI $\mathrm{I}_{(\mathrm{T})}$, LLTM-based $\mathrm{CRI}_{(\mathrm{T})}$ model was able to improve the rapid prediction efficiency of indoor temperature distributions. Figure 6 showed the comparisons of the temperature fields respectively obtained from LLTM-based $\mathrm{CRI}_{(\mathrm{T})}$ and CFD simulations (with inlet-1's temperature set as $20^{\circ} \mathrm{C}$ ). It was found that the temperature distribution results from LLTM-based CRI $\mathrm{T}_{(\mathrm{T})}$ were well consistent with CFD results, with the maximum error less than $2 \%$. Hence, it was considered that LLTM-based CRI $\mathrm{T}_{(\mathrm{T})}$ model can be more efficient for the fast prediction of temperature distributions with less data storage.

On the basis of prediction results about indoor temperature, evaluation index $E_{\mathrm{T}}$ (shown in Eq. (2)) was used to evaluate the balance between indoor thermal comfort (indicated by PMV) and energy consumption (i.e., supply air temperature). With the $E_{\mathrm{T}}$ values for different inlet temperature conditions, the minimum $E_{\mathrm{T}}$ value corresponded to the optimal selection of supply air temperature for inlet-1. Considering that the adjusting range of supplied air temperature was $16-22{ }^{\circ} \mathrm{C}$ (with the summer condition), we obtained the optimal supplied air temperature of $21{ }^{\circ} \mathrm{C}$ in this study. In order to show the control effects with the optimal temperature, Table 6 listed the absolute PMV values corresponding to different supplied air temperatures. From the table, PMV was closest to the desired value of optimal thermal comfort (i.e., PMV $=0$ ) when the inlet-1's temperature equal to $21^{\circ} \mathrm{C}$. Moreover, studies have shown that when the average indoor temperature or the supplied air temperature of air-conditioning system was reduced by $1{ }^{\circ} \mathrm{C}$, the energy consumption of HVAC system could be increased by about $8 \%$ (Cao and Deng 2019). Thus, through the optimal control strategy of inlet temperature, the HVAC system can potentially reduce the energy consumption for cooling loads by about $32 \%$ in this work.

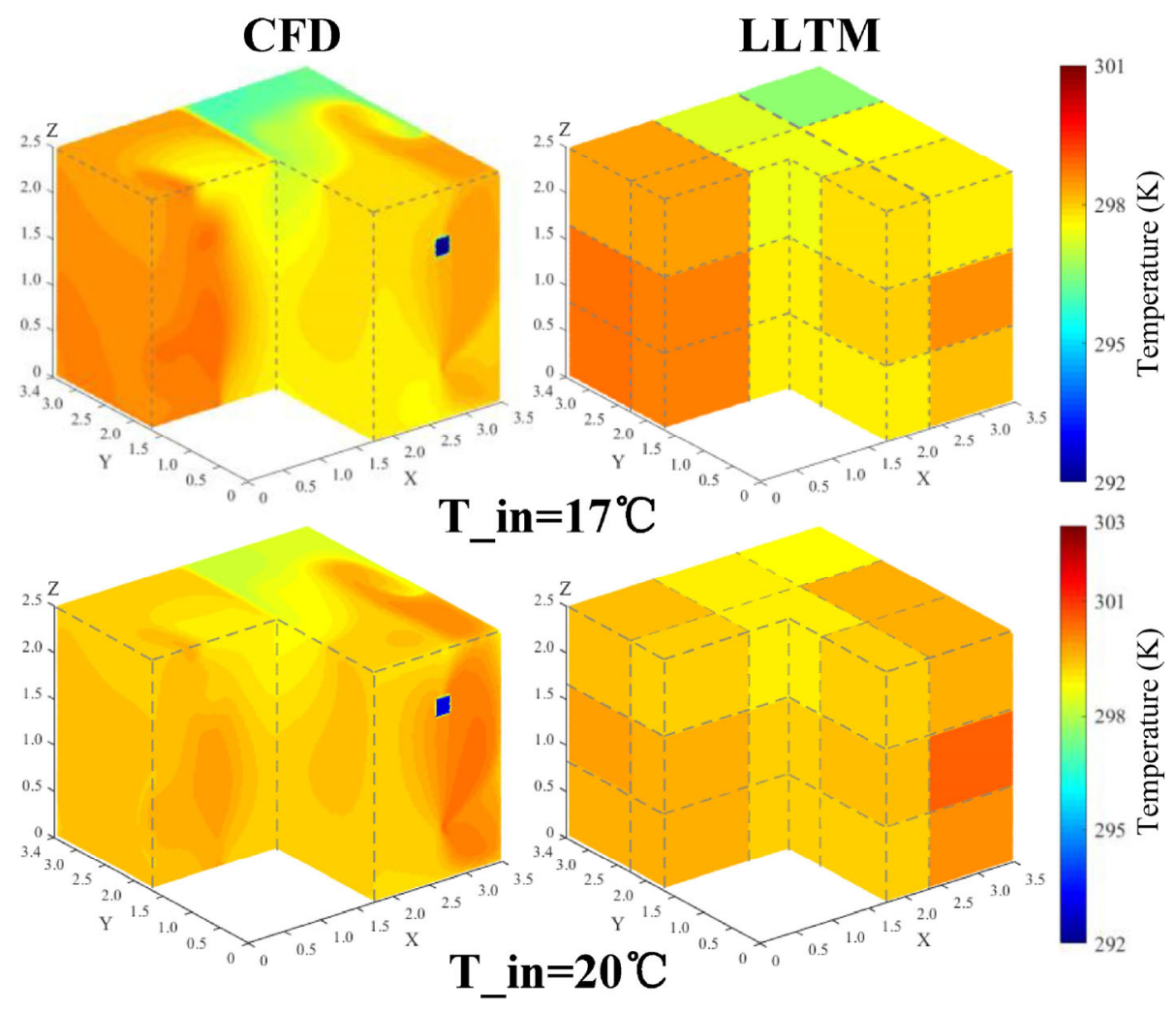

Fig. 5 Comparisons of temperature distribution between CFD and LLTM with two different inlet- 1 temperatures of $17^{\circ} \mathrm{C}$ and $20^{\circ} \mathrm{C}$ 


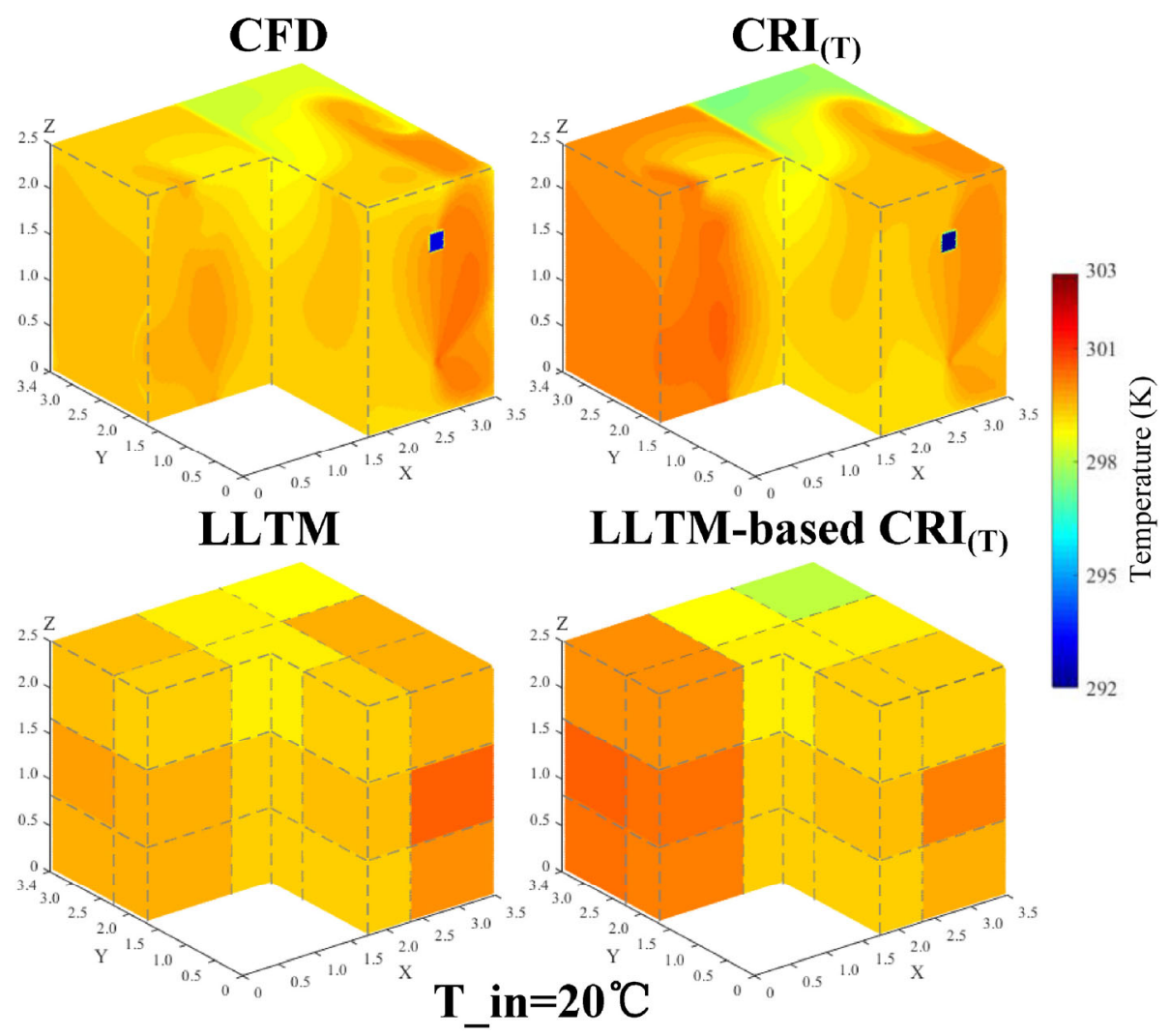

Fig. 6 Comparisons of temperature distributions from CFD and LLTM-based CRI $(\mathrm{T})$ prediction with inlet- 1 temperate set as $20^{\circ} \mathrm{C}$

Table 6 The calculated results of PMV for different inlet-1's temperatures

\begin{tabular}{llllllll}
\hline & $16^{\circ} \mathrm{C}$ & $17^{\circ} \mathrm{C}$ & $18{ }^{\circ} \mathrm{C}$ & $19^{\circ} \mathrm{C}$ & $20^{\circ} \mathrm{C}$ & $21^{\circ} \mathrm{C}$ & $22{ }^{\circ} \mathrm{C}$ \\
\hline$|\mathrm{PMV}|$ & 0.821 & 0.682 & 0.421 & 0.302 & 0.218 & 0.0102 & 0.015 \\
\hline
\end{tabular}

3.3 Step 3: selections of optimal relative humidity using LLHM based-CRI $\left.\right|_{(H)}$ based on optimal ACH and cooling load

\subsubsection{Validation of humidity prediction with LHM and LLHM by using CFD simulations}

The LHM model was firstly validated by CFD simulation. The absolute humidity results from CFD and LHM model were respectively shown in Figures $7(\mathrm{a})$ and (b). The maximum error for CFD and LHM is $13 \%$ (around $1.2 \mathrm{~g} / \mathrm{kg}$ ) under condition of $40 \%$ relative humidity at inlet-2. Moreover, Figure $7(\mathrm{c})$ quantitatively compared the absolute humidity results obtained from LHM and CFD methods at the four positions of $\mathrm{A}(0.875,2.55,1.1) \mathrm{m}, \mathrm{B}(2.625,2.55,1.1) \mathrm{m}, \mathrm{C}$ $(0.875,0.85,1.1) \mathrm{m}$ and $\mathrm{D}(2.625,0.85,1.1) \mathrm{m}$ (along vertical direction). For these four positions, the maximum error of absolute humidity between CFD and LHM was less than $11 \%$ (around $1 \mathrm{~g} / \mathrm{kg}$ ), which appeared at the height of $0.5 \mathrm{~m}$. Generally speaking, the accuracy of LHM could be sufficiently fine for the engineering applications with the acceptable error within $20 \%$.

Then, we further compared the relative humidity results from CFD simulation and LLHM with the conditions of humidity (at inlet-2) equal to $25 \%$ and $30 \%$. As shown in Figure 8, with the amount of CFD data largely decreased, the mean error between CFD and LLHM results were below $4 \%$, which indicated that LLHM method had great performance in the improvement of humidity prediction.

3.3.2 Validation of humidity prediction with $\mathrm{CRI}_{(H)}$ and LLHM based-CRI $I_{(H)}$ method by using CFD simulations

Based on Eq. (4), we calculated the $\mathrm{CRI}_{(\mathrm{H})}$ values with the following conditions that inlet-1's supplied air temperature and relative humidity were respectively equal to $21^{\circ} \mathrm{C}$ and $45 \%$, and inlet-2's supplied air temperature and relative humidity were respectively equal to $26^{\circ} \mathrm{C}$ and $25 \%$. Figure 9 declared the distributions of $\mathrm{CRI}_{(\mathrm{H})}$ at the stereogram perspective and planes of $x=1.75 \mathrm{~m}, y=1.7 \mathrm{~m}$ and $z=$ $1.1 \mathrm{~m}$. The calculated results of $\mathrm{CRI}_{(\mathrm{H})}$ near the inlet- 2 were smaller than the values near the regions of inlet-1, which 

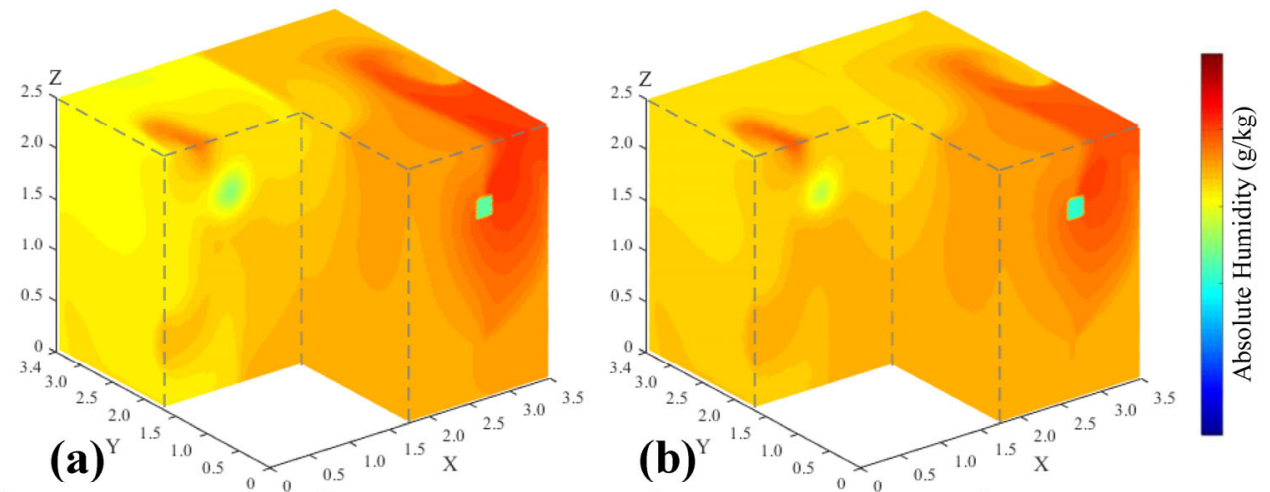

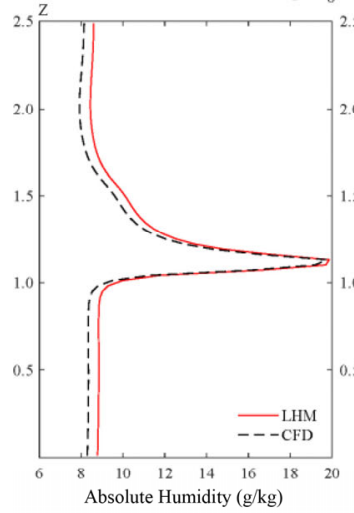

A

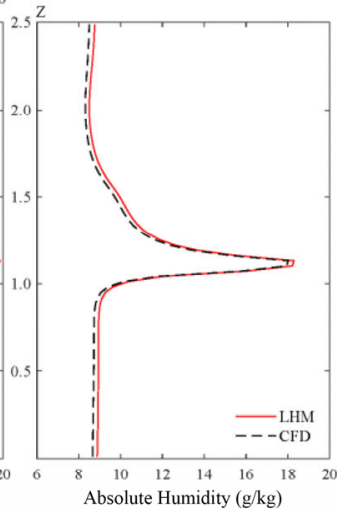

B

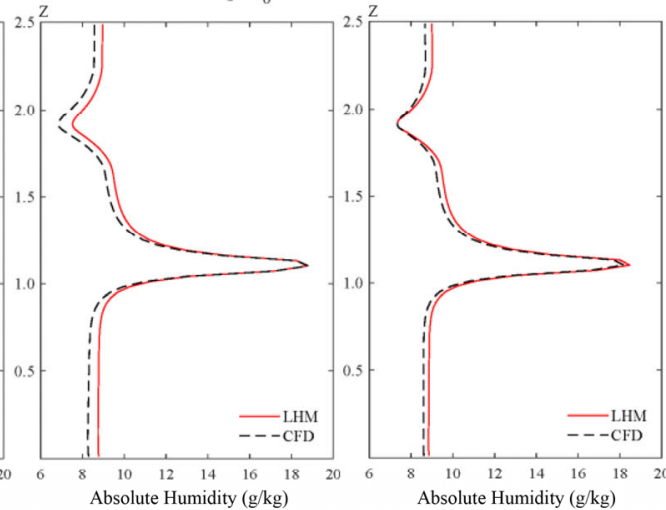

C

D

Fig. 7 Comparisons of humidity distributions using CFD and LHM model with 40\% relative humidity of inlet-2: (a) CFD results; (b) LHM model; (c) the absolute humidity results at position A, B, C, D from CFD simulation and LHM model

\section{CFD}

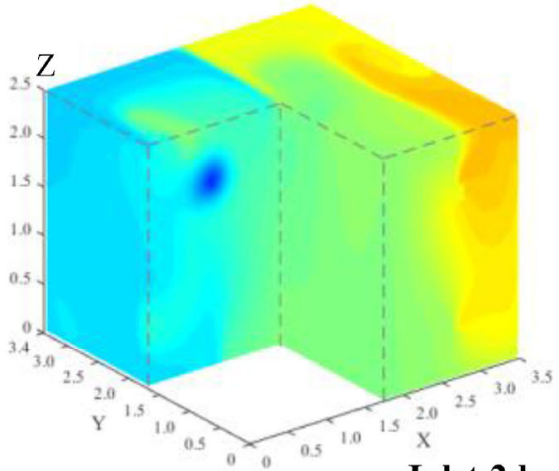

Inlet-2 humidity of $25 \%$

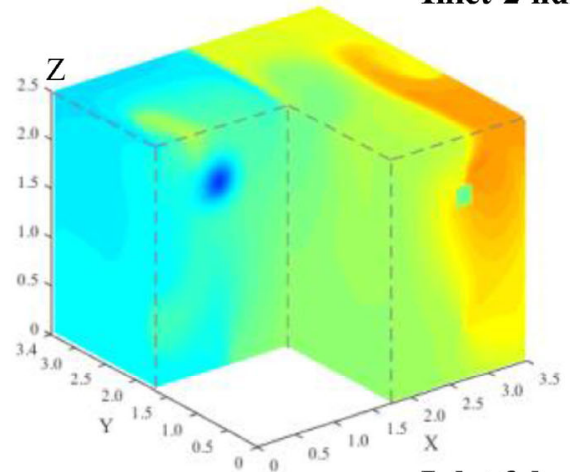

\section{LLHM}
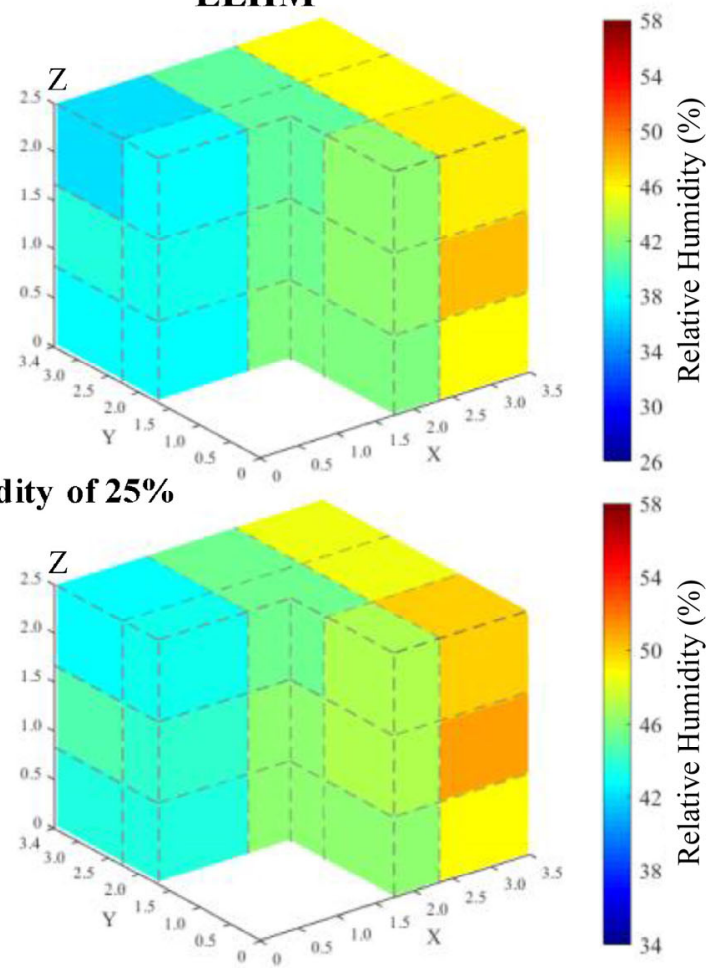

Inlet-2 humidity of $30 \%$

Fig. 8 Comparisons of relative humidity distributions between CFD and LLHM methods with inlet-2 humidity equal to $25 \%$ and $30 \%$ 

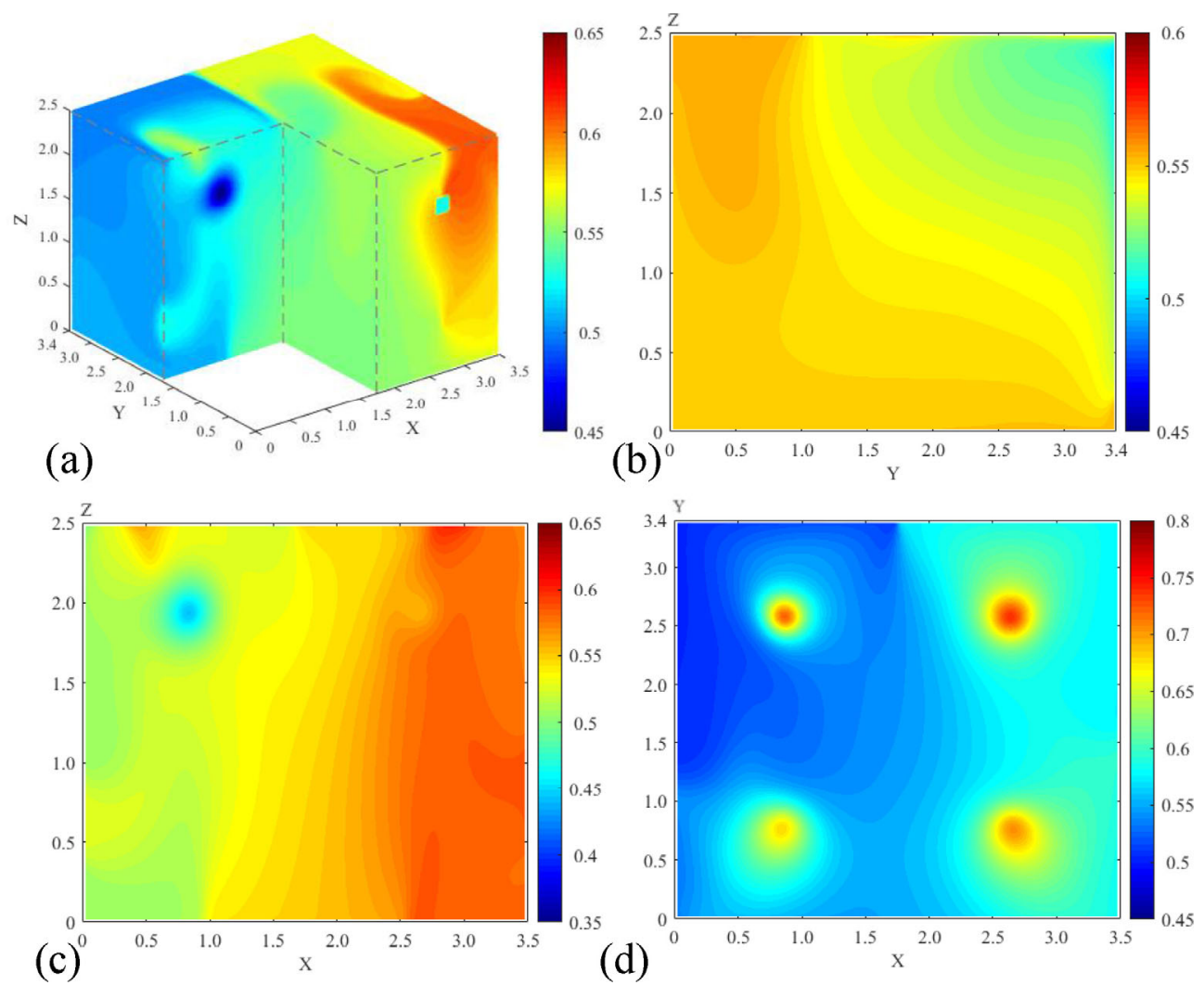

Fig. 9 Calculation results of contribution ratio of indoor humidity $\left(\mathrm{CRI}_{(\mathrm{H})}\right)$ : (a) stereogram; (b) plane of $x=1.75 \mathrm{~m}$; (c) plane of $y=$ $1.7 \mathrm{~m}$; (d) plane of $z=1.1 \mathrm{~m}$

was due to the fact that larger source strength could lead to the greater $\mathrm{CRI}_{(\mathrm{H})}$ values. Then, the $\mathrm{CRI}_{(\mathrm{H})}$ values would be employed to predict indoor humidity distributions. Figure 10 indicated the comparison results of absolute humidity distributions from CFD and $\mathrm{CRI}_{(\mathrm{H})}$ model with inlet-2 relative humidity equal to $30 \%, 40 \%$ and $47 \%$. According to Figure 10, the prediction errors were larger when the relative humidity (at inlet-2) reached up to $40 \%$ and $47 \%$, since the inlet-2's relative humidity differences between initial value (used in the calculation of $\mathrm{CRI}_{(\mathrm{H})}$, equal to 25\%) and increased values (especially for $40 \%$ and $47 \%$ ) were growing synchronously. Nevertheless, the maximum errors between $\mathrm{CRI}_{(\mathrm{H})}$ prediction and $\mathrm{CFD}$ simulation were all within the acceptable limits (i.e., no more than $8 \%$ ).

Combined with well-behaved CRI $\mathrm{CH}_{(\mathrm{H})}$ and LLHM, LLHMbased $\mathrm{CRI}_{(\mathrm{H})}$ model could be utilized to further improve the prediction efficiency of indoor humidity distributions. Figure 11 showed the comparison results of relative humidity between CFD and LLHM-based CRI $\mathrm{I}_{(\mathrm{H})}$ with the inlet-2's supplied relative humidity of air equal to $40 \%$ and $47 \%$ respectively. It can be seen that the results of LLHM-based $\mathrm{CRI}_{(\mathrm{H})}$ were well acceptable with the maximum error of 9\% (around 4\% relative humidity) when compared to CFD results. Thus, LLHM-based $\mathrm{CRI}_{(\mathrm{H})}$ model could also contribute to the rapid prediction and implementation of optimal control for indoor humidity.

\subsubsection{Application of LLHM-based CRI $I_{(H)}$ for the control strategy to balance indoor thermal comfort and energy consumption}

In Step 3, we combined the thermal comfort indicator TS with HVAC system energy consumption (indicated by relative humidity of inlet-2) in the evaluation index $E_{\mathrm{H}}$ to assess the humidity environment for obtaining of the optimal supplied air relative humidity (corresponding to the minimum value of $E_{\mathrm{H}}$ ). Regarding the TS indicator, when the value of TS was close to zero, the comfortable state of indoor personnel should be ideal. For the HVAC energy consumption considered in Step 3, it was analyzed by the co-effects of temperature and humidity on the total energy consumption of integrated HVAC system, which could be more closely matching the real energy consumption of HVAC system during daily regulation. According to Eq. (5), the enthalpy required for the control process is calculated from the outdoor air parameters before control and the indoor air parameters after control as a reference to the energy calculation. In standard GB50736-2012 (2012), it can be obtained that the temperature and humidity parameters for outdoor calculation (taking Guangzhou city as example) 

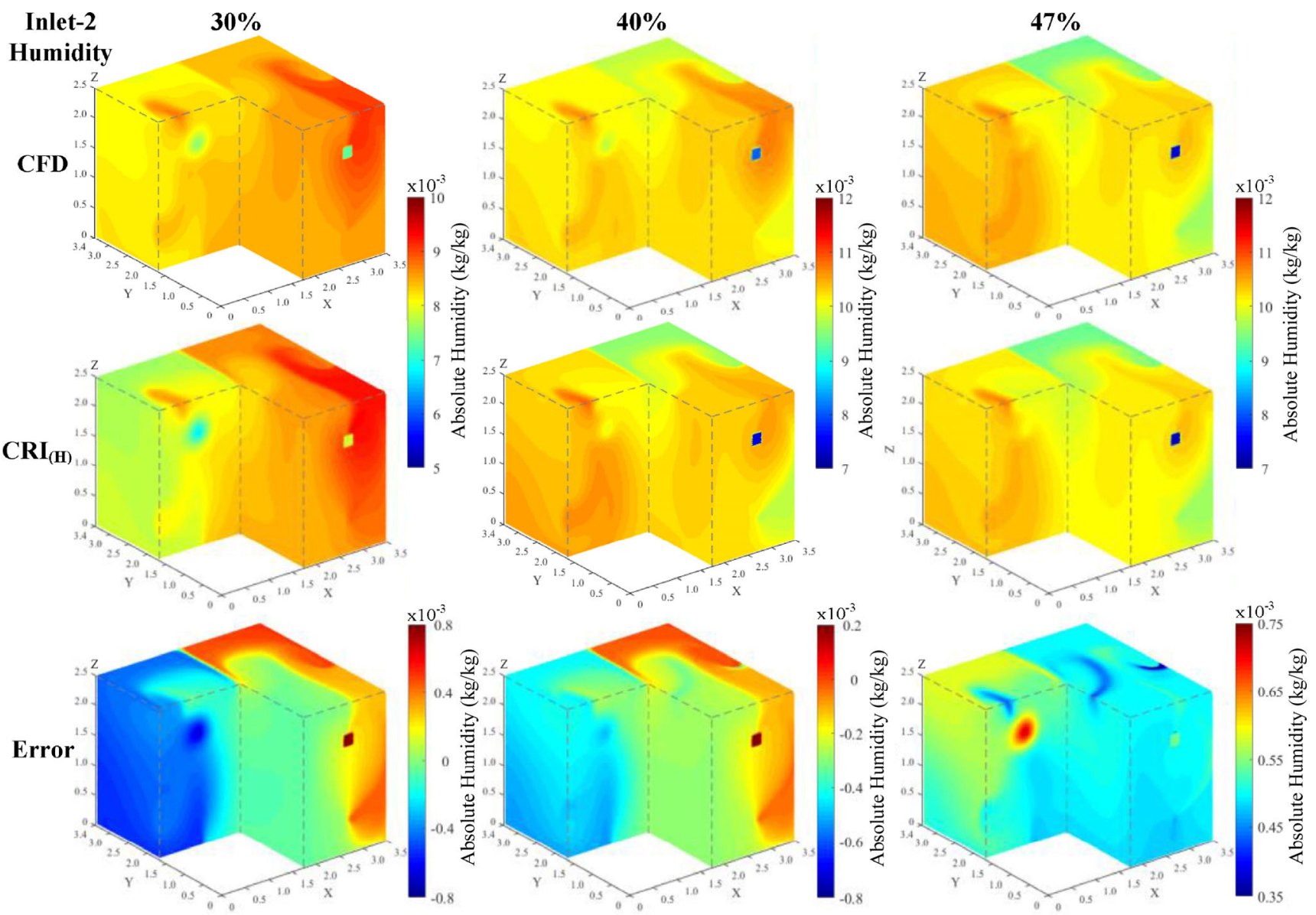

Fig. 10 Comparisons of absolute humidity distribution between $\mathrm{CFD}$ and $\mathrm{CRI}_{(\mathrm{H})}$ model with various inlet-2 relative humidity equal to $30 \%, 40 \%$ and $47 \%$

are respectively corresponding to $30.7^{\circ} \mathrm{C}$ and $68 \%$. Besides, the temperature and humidity parameters at the inlet processed by the traditional HVAC system are corresponding to $16{ }^{\circ} \mathrm{C}$ and $50 \%$. On these bases, the selections of inlet-2's supplied air relative humidity for the optimal control solutions were shown in Table 7, by considering five different conditions of humidity sources (including human body and kettle), and the relative humidity control ranges of inlet- 2 were from $30 \%$ to $60 \%$ (with the optimal inlet-1's supplied air temperature equal to $21^{\circ} \mathrm{C}$ ). It can be seen that the optimal supplied relative humidity of air at inlet- 2 varied between $30 \%$ and $40 \%$. Table 7 also listed the TS values in the occupied areas and energy savings of HVAC system corresponding to the optimal strategies. According to Eq. (5), the enthalpy value required for the operation of air-conditioning system could be rapidly calculated, in order to further obtain the energy saving results. Based on the optimal selections of supplied air relative humidity, the total energy consumption of HVAC system (considering cooling and humidity loads) could be maximally decreased by $35 \%$ (with inlet-2's relative humidity and supplied air temperature corresponding to $40 \%$ and $26^{\circ} \mathrm{C}$ ).

\section{Discussion}

The control of HVAC systems has been a complex issue mainly due to the diversity and dynamic demands of indoor environmental parameters along with a large amount of energy consumption for operation. In this circumstance, the intelligent HVAC control system based on real-time environmental responses was appreciated to achieve the optimal coordination of indoor environmental distributions and energy consumption, including three steps of "monitoring", "prediction" and "control" (Ren and Cao 2020). Of these steps, this work proposed a comprehensive control strategy for the HVAC system corresponding to the third step of intelligent control system. Specifically, by synthesizing our previous studies on the optimal control of ventilation rates (ACHs) (Cao and Ren 2018) and supplied air temperatures (Ren and Cao 2019a), the rapid prediction of multiple indoor parameters (i.e., pollutant concentration, temperature and humidity) and the optimal regulation of supply air parameters (i.e., $\mathrm{ACH}$, temperature and humidity) for integrated HVAC system control were well implemented, on the basis of the coupling prediction models with low- 


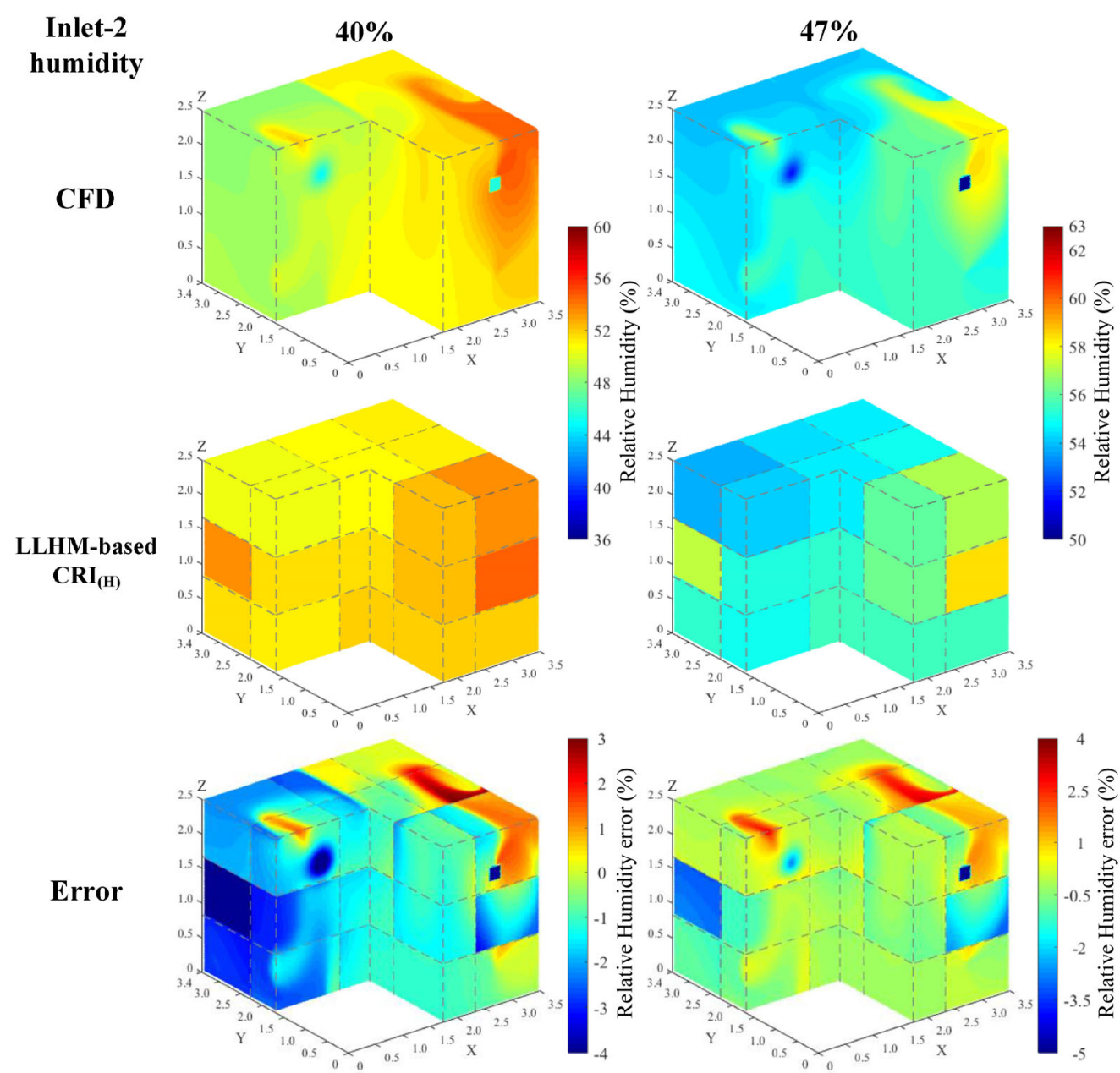

Fig. 11 Comparisons of relative humidity distribution between CFD and LLHM-based $\mathrm{CRI}_{(\mathrm{H})}$ with the inlet-2's supplied air relative humidity equal to $40 \%$ and $47 \%$

Table 7 Selection results of supplied air relative humidity for the optimal control strategy with corresponding TS values in the occupied areas and energy savings of HVAC system (considering different humidity conditions of humidity source including human body and kettle)

\begin{tabular}{|c|c|c|c|c|c|c|}
\hline \multicolumn{4}{|c|}{ Indoor humidity conditions $(\mathrm{g} / \mathrm{h})$} & \multicolumn{3}{|c|}{ Control strategies corresponding to the minimum $E_{\mathrm{H}}$ (control range of relative humidity at inlet-2: $30 \%-60 \%$ ) } \\
\hline A & B & $\mathrm{C}$ & $\mathrm{D}$ & Optimal humidity & TS & Energy saving \\
\hline 60 & 60 & 60 & 60 & $40 \%$ & -0.008 & $35 \%$ \\
\hline 100 & 60 & 60 & 60 & $30 \%$ & -0.05 & $24 \%$ \\
\hline 100 & 100 & 60 & 60 & $35 \%$ & -0.009 & $29 \%$ \\
\hline 100 & 100 & 100 & 60 & $35 \%$ & 0.003 & $29 \%$ \\
\hline 100 & 100 & 100 & 100 & $30 \%$ & 0.007 & $24 \%$ \\
\hline
\end{tabular}

dimensional linear models and two rapid prediction models (i.e., LLVM-based ANN, LLTM-based CRI ${ }_{(\mathrm{T})}$, LLHM-based $\left.\mathrm{CRI}_{(\mathrm{H})}\right)$. Besides, three evaluation indicators $\left(E_{\mathrm{V}}, E_{\mathrm{T}}, E_{\mathrm{H}}\right)$ were also adopted to realize the efficient evaluations of supply air parameters and energy consumption to contribute to the optimal and synthetically control strategies of HVAC system.

However, in order to improve the applicability of above- mentioned intelligent HVAC control system, "monitoring" part and real-life control system combined with the optimal control strategies needed to be focused on as well. Regarding the monitoring step of HVAC control system, we should apply the monitoring technology to obtain the real-time data of indoor environmental parameters, so that the HVAC control system is able to quickly respond to the real demand of indoor environment with the online monitoring data as 
inputs. Considering that more monitoring sensors may call for larger expense and installing space towards actual building environment, Ren and Cao (2019b) used limited number of sensors to monitor the concentration of indoor pollutants. From the findings, it was concluded that the prediction of environmental fields showed the satisfying performance as the sensor numbers equal to 5 , regardless of sensor locations. Nevertheless, when using 3 or 4 sensors, there was an occasional error appearing in the prediction results, which had a great relationship to the sensor layout. Then, in order to achieve the optimal layout strategies with fewer sensors (e.g., 3 sensors), Cao et al. (2020) investigated the systematic sensor deployment method by using clustering model of fuzzy C-means (FCM) algorithm for the efficient prediction of indoor environments. From the above, the well-behaved limited monitoring technology could be promising for the development of intelligent HVAC control system, which should be further incorporated into the comprehensive control strategies presented in this work.

In addition, there are some limitations of this work, as follows. (1) This work used a full fresh air system for case study and simulation. To achieve the purposes of economic and energy saving, the return air conditioning system should be focused on in our future work. (2) The method proposed in this work was mainly based on the linear principle to achieve the step-by-step control of HVAC system. In our future work, we will consider the interactions among different environmental factors to achieve comprehensive control of HVAC system. (3) The design of the actual control system for temperature and humidity has not been implemented in this work. According to our previous work, the ventilation rate was adjusted corresponding to the variation of fan voltage (Zhu et al. 2020; Ren and Cao 2020). Thus, we can also adjust the compressor speed (i.e., compressor input voltage) of HVAC system to obtain different inlet temperature and humidity, in order to achieve the effective regulation of integrate air conditioning system (Zhong et al. 2017). To sum up, the future work will focus on improving the applicability of actual HVAC control system for the real-life building environment.

\section{Conclusion}

The purpose of this work was to provide fast prediction models for indoor environmental parameters (i.e., air pollutant concentration, temperature and humidity), with a final goal to realize on line control of HVAC systems through the sequential regulations of optimal $\mathrm{ACH}$, supplied air temperature and humidity. This work will further contribute to the balancing between air-conditioning energy consumption (including ventilation, cooling and humidity loads) and indoor environmental quality. Of this study, indoor environmental distributions (i.e., $\mathrm{CO}_{2}$ concentration, temperature and humidity fields) can be rapidly predicted based on the coupling models with low-dimensional linear models (LLM), artificial neural network (ANN) and contribution ratio of indoor climate (CRI), i.e., LLVMbased ANN, LLTM-based CRI $(\mathrm{T})$ and LLHM-based CRI $\mathrm{CH}_{(\mathrm{H})}$ models. The optimal control strategies for $\mathrm{ACH}$, supplied air temperature and relative humidity were respectively implemented with the three self-defined evaluation indices $\left(E_{\mathrm{V}}, E_{\mathrm{T}}\right.$ and $\left.E_{\mathrm{H}}\right)$. The main conclusions are summarized as follows.

(1) The deviation errors between the prediction results of linear humidity model (LHM) and CFD results were less than $15 \%$. Considering the well-behaved linear models (i.e., LVM's error less than 13\% and LTM's error less than 20\%) proposed in our previous work (Cao and Ren 2018; Ren and Cao 2019a; Zhu et al. 2020), the adoption of linear models could show favorable performance in the rapid prediction of indoor environmental fields.

(2) The well-behaved $\mathrm{CRI}_{(\mathrm{H})}$ model was utilized to rapidly predict indoor humidity, and the maximum prediction error compared to CFD results was less than $15 \%$.

(3) Through using LLVM-based ANN, LLTM-based CRI $\mathrm{I}_{(\mathrm{T})}$ and LLHM-based $\mathrm{CRI}_{(\mathrm{H})}$, low-dimensional indoor environmental fields (i.e., $\mathrm{CO}_{2}$, temperature and humidity fields) could be effectively predicted with the maximum error less than $15 \%$. On account of evaluation indices $\left(E_{\mathrm{V}}, E_{\mathrm{T}}, E_{\mathrm{H}}\right)$, the integrated HVAC system can be effectively regulated to save the maximum energy consumption by $35 \%$ and ensure acceptable indoor thermal comfort environment (i.e., $\mathrm{TS} \approx 0$ ).

From the above, the integrated HVAC control strategy proposed in the current work could be beneficial to the management of HVAC control system in the perspectives of energy saving and human health. However, several limitations should also be noticed in this work, such as ignoring the applicability of control strategies to the actual air-conditioning system for the complex building environments. Moreover, the current study of HVAC system control was carried out based on CFD simulation, without taking the real-time responses of indoor environment into account. The future work will further develop and implement the real-life and intelligent HVAC control system for the actual various building environments.

\section{Acknowledgements}

The authors would like to acknowledge the funding support from National Natural Science Foundation of China (No. 51778385).

Electronic Supplementary Material (ESM): supplementary 
material is available in the online version of this article at https://doi.org/10.1007/s12273-020-0709-z.

Open Access: This article is licensed under a Creative Commons Attribution 4.0 International License, which permits use, sharing, adaptation, distribution and reproduction in any medium or format, as long as you give appropriate credit to the original author(s) and the source, provide a link to the Creative Commons licence, and indicate if changes were made.

The images or other third party material in this article are included in the article's Creative Commons licence, unless indicated otherwise in a credit line to the material. If material is not included in the article's Creative Commons licence and your intended use is not permitted by statutory regulation or exceeds the permitted use, you will need to obtain permission directly from the copyright holder.

To view a copy of this licence, visit http://creativecommons.org/licenses/by/4.0/

\section{References}

Anand P, Cheong D, Sekhar C (2020). Computation of zone-level ventilation requirement based on actual occupancy, plug and lighting load information. Indoor and Built Environment, 29: 558-574.

ASHRAE (2009). ASHRAE Handbook: Fundamentals. Atlanta: American Society of Heating, Refrigerating and Air-Conditioning Engineers.

Bluyssen PM, Aries M, van Dommelen P (2011). Comfort of workers in office buildings: The European HOPE project. Building and Environment, 46: 280-288.

Cao S-J, Zhu D-H, Yang Y-B (2016). Associated relationship between ventilation rates and indoor air quality. RSC Advances, 6: 111427111435.

Cao S-J, Ren C (2018). Ventilation control strategy using lowdimensional linear ventilation models and artificial neural network. Building and Environment, 144: 316-333.

Cao S-J (2019). Challenges of using CFD simulation for the design and online control of ventilation systems. Indoor and Built Environment, 28: 3-6.

Cao S-J, Deng H-Y (2019). Investigation of temperature regulation effects on indoor thermal comfort, air quality, and energy savings toward green residential buildings. Science and Technology for the Built Environment, 25: 309-321.

Cao S-J, Ding J, Ren C (2020). Sensor deployment strategy using cluster analysis of Fuzzy C-Means Algorithm: Towards online control of indoor environment's safety and health. Sustainable Cities and Society, 59: 102190.

Chen C, Zhao B, Lai D, Liu W (2018). A simple method for differentiating direct and indirect exposure to exhaled contaminants in mechanically ventilated rooms. Building Simulation, 11: 1039-1051.

Chow WK (2002). Ventilation of enclosed train compartments in Hong Kong. Applied Energy, 71: 161-170.

Deng Y, Feng Z, Fang J, Cao S-J (2018). Impact of ventilation rates on indoor thermal comfort and energy efficiency of ground-source heat pump system. Sustainable Cities and Society, 37: 154-163.

Egawa M, Oguri M, Kuwahara T, Takahashi M (2002). Effect of exposure of human skin to a dry environment. Skin Research and Technology, 8: 212-218.

Fang X, Winkler J, Christensen D (2011). Using EnergyPlus to perform dehumidification analysis on Building America homes. HVAC\&R Research, 17: 268-283.

Feng Z, Zhou X, Xu S, Ding J, Cao S-J (2018). Impacts of humidification process on indoor thermal comfort and air quality using portable ultrasonic humidifier. Building and Environment, 133: 62-72.

Fisk WJ, Lei-Gomez Q, Mendell MJ (2007). Meta-analyses of the associations of respiratory health effects with dampness and mold in homes. Indoor Air, 17: 284-296.

Ganchev I, Taneva A, Kutryanski K, Petrov M (2019). Decoupling fuzzy-neural temperature and humidity control in HVAC systems. IFAC-PapersOnLine, 52: 299-304.

GB50019-2003 (2004). Code for Design of Heating Ventilation and Air Conditioning. Ministry of Construction of China. (in Chinese)

GB50736-2012 (2012). Design Code for Heating, Ventilation and Air Conditioning in Residential Buildings. Ministry of Housing and Urban-Rural Development of China. (in Chinese)

Grosskopf KR, Oppenheim P, Brennan T (2008). Preventing defect claims in hot, humid climates. ASHRAE Journal, 50(7): 40-41.

Gul MS, Patidar S (2015). Understanding the energy consumption and occupancy of a multi-purpose academic building. Energy and Buildings, 87: 155-165.

Hashiguchi N, Hirakawa M, Tochihara Y, Kaji Y, Karaki C (2005). Thermal environment and subjective responses of patients and staff in a hospital during winter. Journal of Physiological Anthropology and Applied Human Science, 24: 111-115.

He M, Li N, He Y, He D, Wang K (2017). Influences of temperature and humidity on perceived air quality with radiant panel workstation. Procedia Engineering, 205: 765-772.

Huang H, Kato S, Hu R, Ishida Y (2011). Development of new indices to assess the contribution of moisture sources to indoor humidity and application to optimization design: Proposal of CRI(H) and a transient simulation for the prediction of indoor humidity. Building and Environment, 46: 1817-1826.

Jaakkola K, Saukkoriipi A, Jokelainen J, Juvonen R, Kauppila J, et al. (2014). Decline in temperature and humidity increases the occurrence of influenza in cold climate. Environmental Health, 13: 22.

Jia J, Lee WL (2015). Experimental investigations on using phase change material for performance improvement of storage-enhanced heat recovery room air-conditioner. Energy, 93: 1394-1403.

Kim JT, Yu CWF (2018). Sustainable development and requirements for energy efficiency in buildings-The Korean perspectives. Indoor and Built Environment, 27: 734-751.

Lai D, Chen B, Liu K (2020). Quantification of the influence of thermal comfort and life patterns on outdoor space activities. Building Simulation, 13: 113-125.

Li W, Koo C, Cha SH, Hong T, Oh J (2018). A novel real-time method for HVAC system operation to improve indoor environmental quality in meeting rooms. Building and Environment, 144: 365-385. 
Moroşan PD, Bourdais R, Dumur D, Buisson J (2010). Building temperature regulation using a distributed model predictive control. Energy and Buildings, 42: 1445-1452.

Paasi J, Nurmi S, Vuorinen R, Strengell S, Maijala P (2001). Performance of ESD protective materials at low relative humidity. Journal of Electrostatics, 51-52: 429-434.

de Paula Xavier AA, Lamberts R (2000). Indices of thermal comfort developed from field survey in Brazil. ASHRAE Transactions, 106(1): 45-58.

Pérez-Lombard L, Ortiz J, Pout C (2008). A review on buildings energy consumption information. Energy and Buildings, 40: 394-398.

Popescu-Croitoru C (2011). Theoretical and experimental studies concerning the influence of air turbulence in conditioned rooms on thermal comfort. PhD Thesis, Technical University of Civil Engineering, Romania.

Razjouyan J, Lee H, Gilligan B, Lindberg C, Nguyen H, et al. (2020). Wellbuilt for wellbeing: Controlling relative humidity in the workplace matters for our health. Indoor Air, 30: 167-179.

Ren C, Cao S-J (2019a). Development and application of linear ventilation and temperature models for indoor environmental prediction and HVAC systems control. Sustainable Cities and Society, 51: 101673.

Ren J, Cao S-J (2019b). Incorporating online monitoring data into fast prediction models towards the development of artificial intelligent ventilation systems. Sustainable Cities and Society, 47: 101498.

Ren C, Cao S-J (2020). Implementation and visualization of artificial intelligent ventilation control system using fast prediction models and limited monitoring data. Sustainable Cities and Society, 52: 101860.

Sato M, Fukayo S, Yano E (2003). Adverse environmental health effects of ultra-low relative humidity indoor air. Journal of Occupational Health, 45: 133-136.

Shehadi M (2018). Review of humidity control technologies in buildings. Journal of Building Engineering, 19: 539-551.
Tian S, Su X, Shao X, Wang L (2020). Optimization and evaluation of a solar energy, heat pump and desiccant wheel hybrid system in a nearly zero energy building. Building Simulation, https://doi.org/10.1007/s12273-020-0627-0

Wang H, Wang G, Li X (2020). Implementation of demand-oriented ventilation with adjustable fan network. Indoor and Built Environment, 29: 621-635.

Yuan X, Pan Y, Yang J, Wang W, Huang Z (2020). Study on the application of reinforcement learning in the operation optimization of HVAC system. Building Simulation, https://doi.org/10.1007/ s12273-020-0602-9

Zhang W, Hiyama K, Kato S, Ishida Y (2013). Building energy simulation considering spatial temperature distribution for nonuniform indoor environment. Building and Environment, 63: 89-96.

Zhang T, Liu X, Jiang Y (2014). Development of temperature and humidity independent control (THIC) air-conditioning systems in China-A review. Renewable and Sustainable Energy Reviews, 29: 793-803.

Zhang S, Cheng Y, Huan C, Lin Z (2019). Equivalent room air temperature based cooling load estimation method for stratum ventilation and displacement ventilation. Building and Environment, 148: 67-81.

Zhong Z, Xu X, Zhang X, Huang Z (2017). Simulation based control performance evaluation of a novel fuzzy logic control algorithm for simultaneously controlling indoor air temperature and humidity using a direct expansion (DX) air-conditioning (A/C) system. Procedia Engineering, 205: 1792-1799.

Zhu H, Yu CW, Cao S (2020). Ventilation online monitoring and control system from the perspectives of technology application. Indoor and Built Environment, 29: 587-602.

Zhuang C, Wang S (2020). Uncertainty-based robust optimal design of cleanroom air-conditioning systems considering life-cycle performance. Indoor and Built Environment, https://doi.org/10.1177/ 1420326 X19899442 